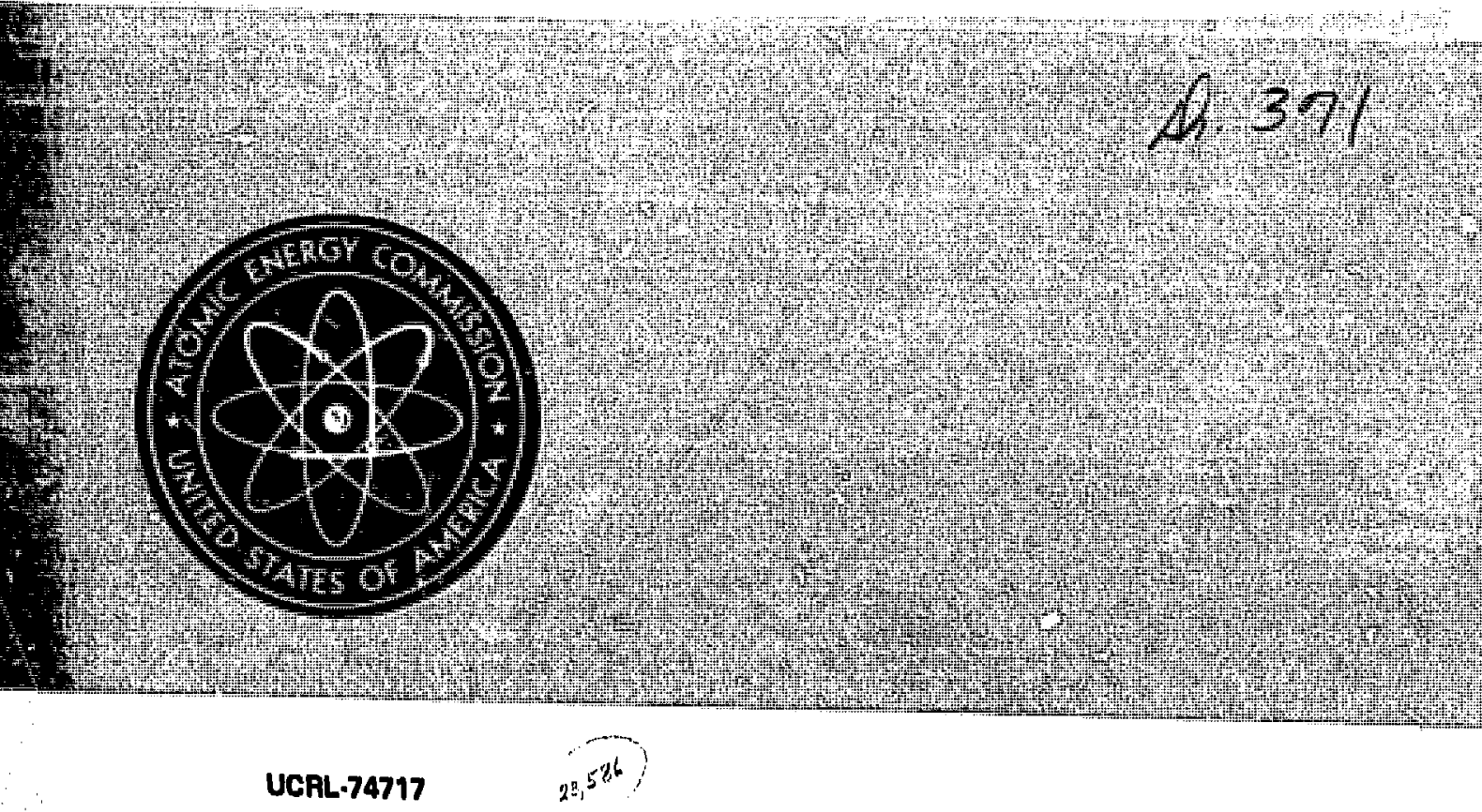

\title{
QUANYITATIVE NONDISPERSIVE X-RAY FLUORESCENCE ANALYSIS OF HIGHLY RADIOACTIVE SAMPLES FOR URANIUM AND PLUTONIUM CONCENTRATION
}

Auguat 14, 1873

Lawrence Livermore Laboratory

University of Callifornie

Livermore, California

\section{MASTER}

DISTRIBUTION OF THIS DOCUMENT IS UNLIMITED

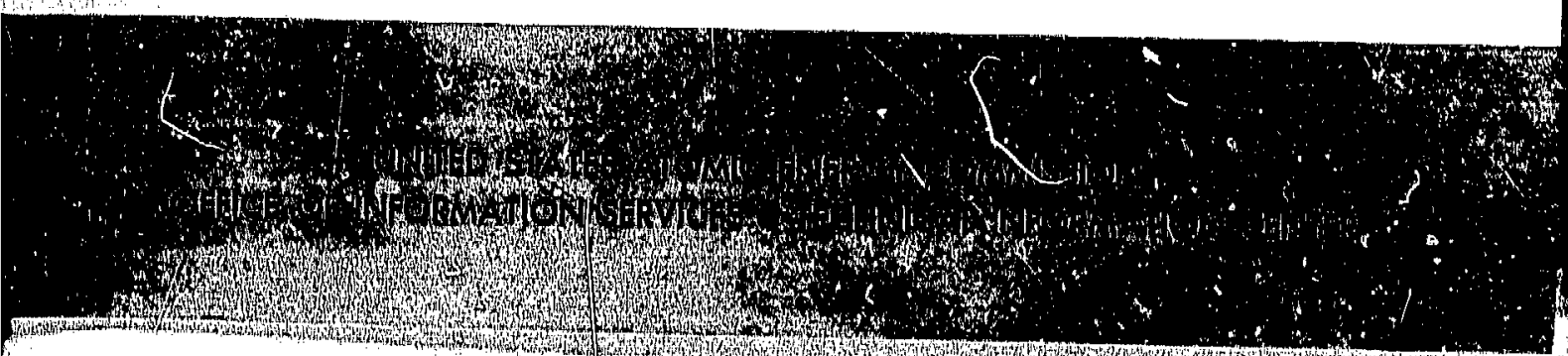


Other lasues of this report may bear the number COII-730830-2

\section{NOTICE}

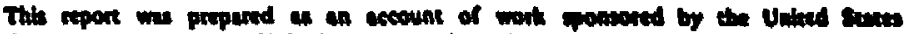

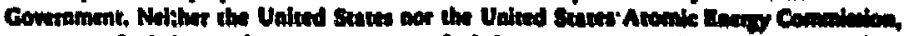

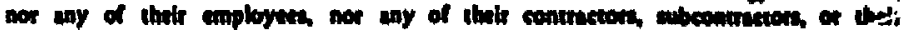

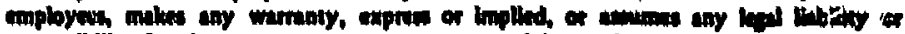

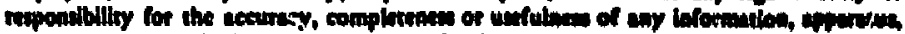

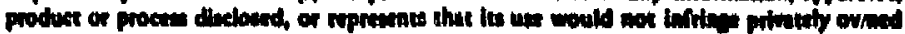
intus.

This report has been reproduced directly from the bext available cepy.

Avilable from the National Technical Information Servies, U. 5. Department of Commeres, Springfilda, Virginia 22131.

Price: Papet Cogy S4.00

Mierofiche $\mathbf{0 . 9 5}$ 
UCRL-74717

Dintibution Category UC-15

\section{년 \\ LAMRENCE LMEPMORE LABORATOFY

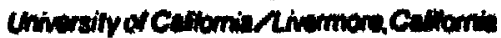

QUANTITATIVE MONDISPERSIVE $X$-RAY FUURESCENCE ARHLYSIS OF HIGHL

RADIOACTIVE SNAPLES FOR URANIUA AND PLUTONIUA CONCENTRATLON

W. L. Plek1es

J. L. Cate, Jr.

August 14, 1973

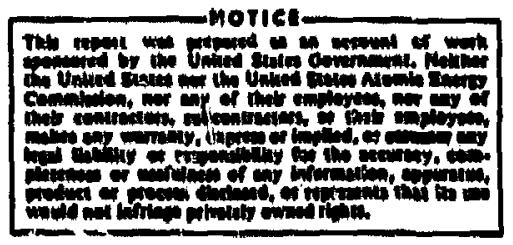

Presented at 22nd Confersuce on Applications of $x$-Ray Analysis, Auguet 22-24, 1973, Damver, Colorado

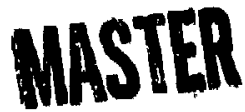


QUANTITATIVE NONDISPERSIVE X-RAY FLUORESCENCE ANALYSIS OF HIGHLY RADIOACTIVE SAMPLES FOR URANIUM AND PLUTONIUM CONCENTRATION"

W. L. Pickles and J. L, Cate, Jr.

Lawrence Livermore Laboratory, Univarsity of California

Livermore, California 94550

\section{ABSTRACT}

Fluorescent $x$-ray energy spoctra woro successfully acquired from uranlum and plutoniule in 400:1 ratios in samples contalning $2 \mathrm{CX} / \mathrm{gram}$ of mixed fisstion products. The analyeical system consists of a silver transpission anode $x$-ray tube, a low-z scattering clumber, a magnetic B-ray trap, a beam monitor prabe, a commerclal Si(Li) detector, a set af modifted electronics to hanille the large $\gamma$-ray overlosd rate, and a computer analyzer using a higher-level language to handle data reduction.

The computer programs used to obtain peak areas from the closely spaced uranium and plutonium (La 1+2) peaks were constructed to wake use of knowledge of uppor-edge tailing gained in this oxperiment. Programs are being develaped to properly remove background under the uranium and plutonium peaks. Absorption offects in the larger samples have been measured using the ratlo of uranium (Li) to uranium (LY) peak area and are incorporated in the detaanalysis schemes. A titanium monttor probe, consisting of a fixed tieanium plate noar the sample, Introducos a constunt-eren titaniun $K \times-r a y$ line into the spectrum. The program uses the area of this peak to correct for effects of total oxciting flux, geometry, and system dead-time losses. Standard semples of varlous types are used to generate calibration curves from which quantitative results are obtained,

Samples are taken from dissolved high-burnup power-reactor tuel rods. The Ilquid sample is actule and has a radiction lovel at one foot of approximetely $2 \mathrm{R} / \mathrm{hr} B$ and $300 \mathrm{mR} / \mathrm{hr} \mathrm{r}$. Sarple 
propasation involves only the evaporation of the liquid sample on a $1 / 2-m i l$ polycarbonate substrate and subsequent sealing with another layer of polycarbonate film. The samples are then mounted in standard 35-mm slide-holders.

Preliminary testing on a limited number of propared uranjum and plutonium samples indicates a precision of about 18 and an accuracy of about 28, over a range of 1 to $58 \mathrm{\mu g}$ total mass. The samples have not yot been verified by independent chemical analysis. The system has been installed at the AEC Savannah Rivar facility for extensive testing.

\section{INTRODUCTION}

The prototypo nondispersive $x$-ray fluorescence system assembled and put into operation in a test and ovaluation jrogram at du Pont Savannah River Plant is intended to analyze "hot" dissolver solutions for olemental uranil'm and plutunium concentrations with a ainimum of sanple proparation and without ths removal of tha copious quantitios of sadioactive mixod fission products present. The solutions obtalned by dissolving fuel rods from power rekctars have uranium concentrations of about $50 \mathrm{~g} / 11$ ter, uranium to plutonium ratios ranging from 80 to $40 \mathrm{C}$, and radiation lovels of abnut $2 \mathrm{Ct} / 8$ $(\beta, \gamma)$.

\section{SYSTEM DESCRIPTYON}

The system is made up of throe parts: a movable undt (F18. R), referred to as tha "X-ray data heed," a computer analyzer, and a sample preparation stand.

The $x$-ray data head requires only 110 V AC power and a periodfe 1iquid-nitrogen fill for the detector. It contains the tube-exciter system, the scattering chamber to hold the samples, a S1(Li) detector, and all the power supplies and electronics needed to produce the signal used for analysis. The following sectlongl describe the subsystems that make up the $X$-ray date head. Figure 2 is a schematic drawing of the unit, and Pigures 3,4 , and 5 are photographs for clarffication of the description.

\section{$X$-Ray Tube Exciter}

The $x$-ray tubo oxciter is a pumpable, silver transmission anode of the air-cooled typo, slaliar to that described by Jacklevic (1). This tube dissipates up to $50 \mathrm{~W}$ and delivers a flux of approxiwately $10^{10}$ photons/ $\mathrm{cm}^{2}$ por second at the sample $(3-5 \mathrm{R} / \mathrm{sec})$. The 


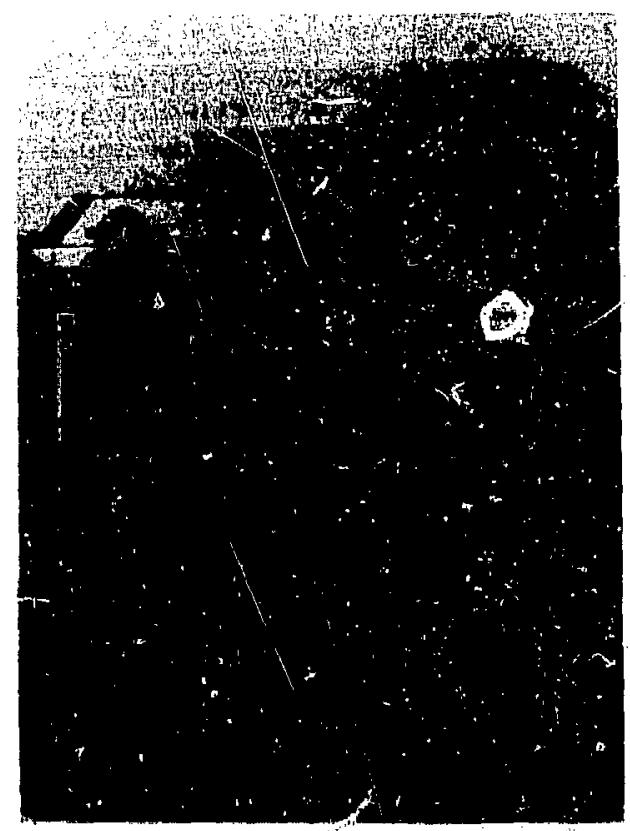

Figure 1. X-ray data head, showing complete movable unit.

energy spostrum of the photon beam is shown in Fig. 6. The quality of the beam is expressed by the percent of the total rlux in each of four reglons. Region II contrilutes the major part of the Compton-scattered background under the peak used for analysis (urassium (La)), F.egions III and IV are avallable for excitation of the sample, und comprise about 958 of the syectrum. The tube can bu cycled up to air, have the target changed to another material, and be producing a useful $x$-ray beaul in about 30 minutes. The tube is ovacuated by a comblnation of a cryogenic molecular-sieve roughing pump, and on 8-11ter/sec Ion pump; the operafing pressure is approxinately $10^{-7}$ torr.

The phoeen beam can be varind by both the fllament current and the grid cap bias. The been flux has boen neasured to be stable and resettablo to 14 ( 1 sigmo),

The constmuction of this tube is difficult, but we have found it to be very roliabio in oporation. 


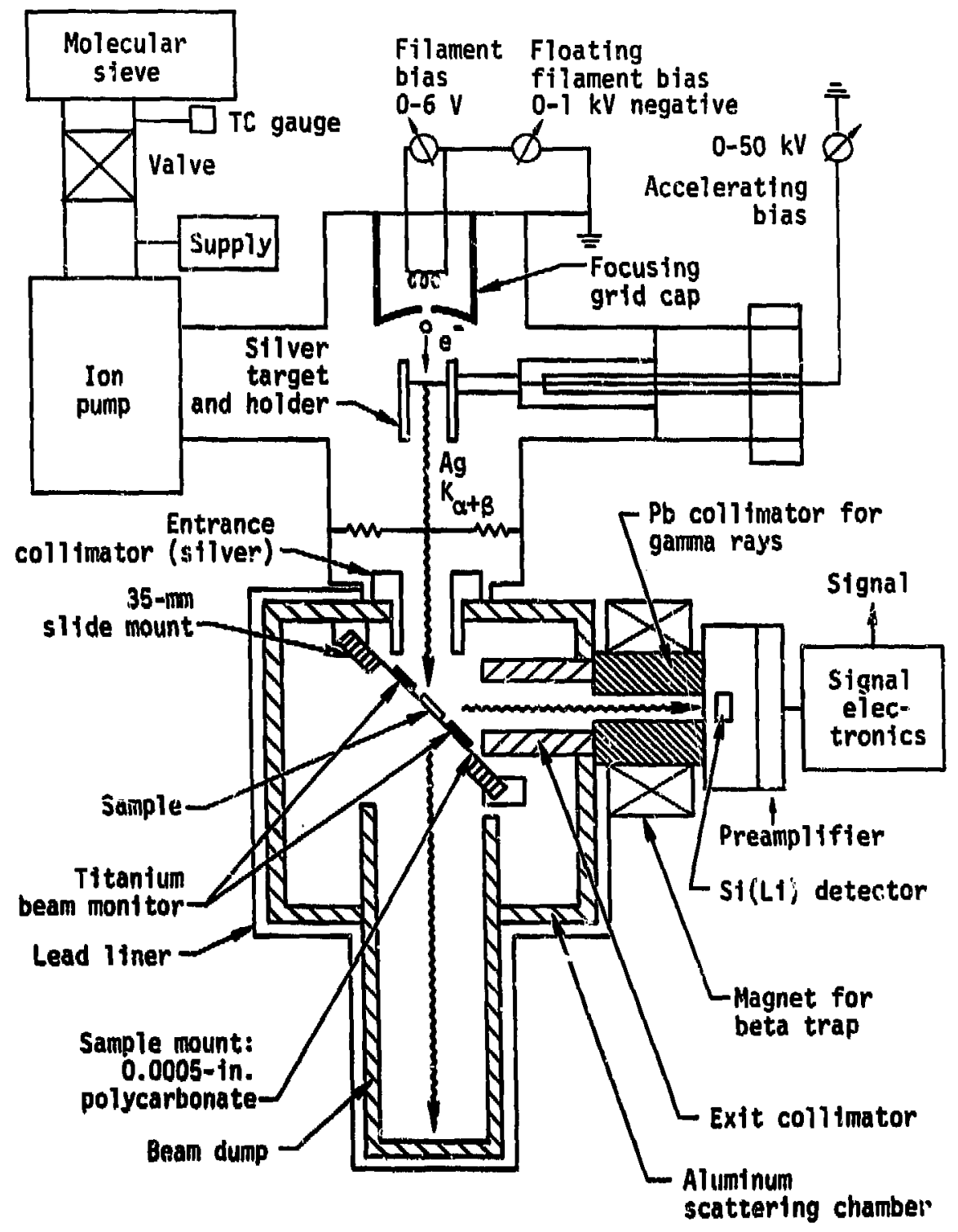

Figure 2. Schematte drawing of equipment contained in the "x-ray data head" unit. 


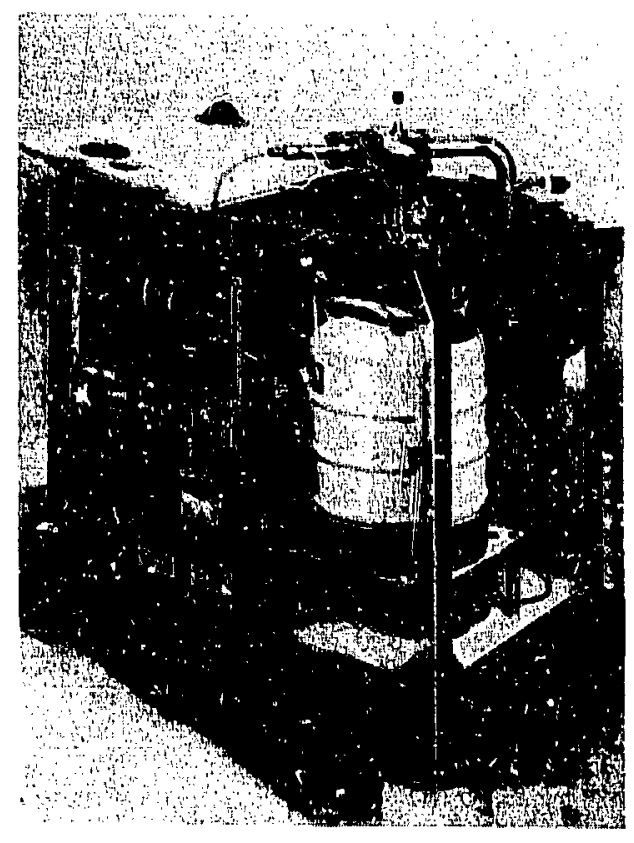

Figure 3. X-ray data head, front view.

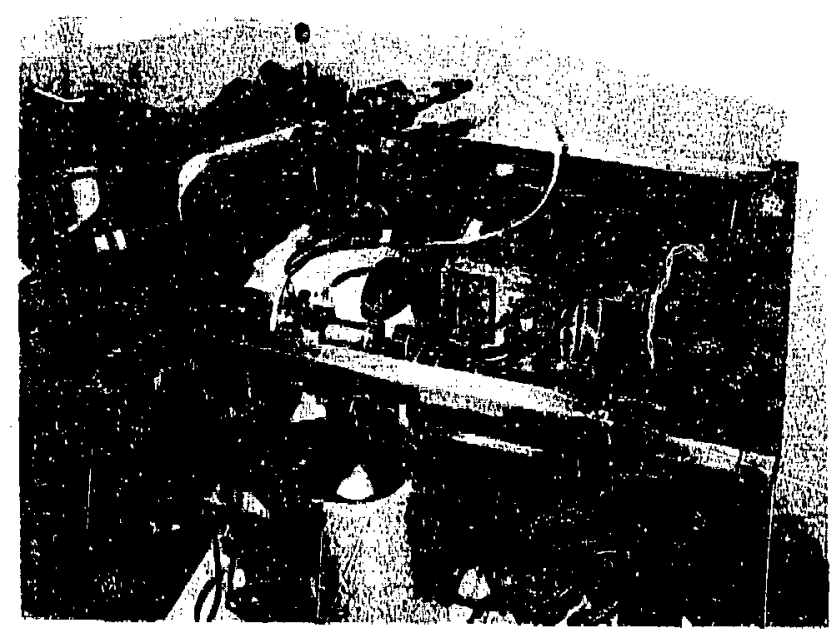

Pigure 4. X-ray data head, rear view. 


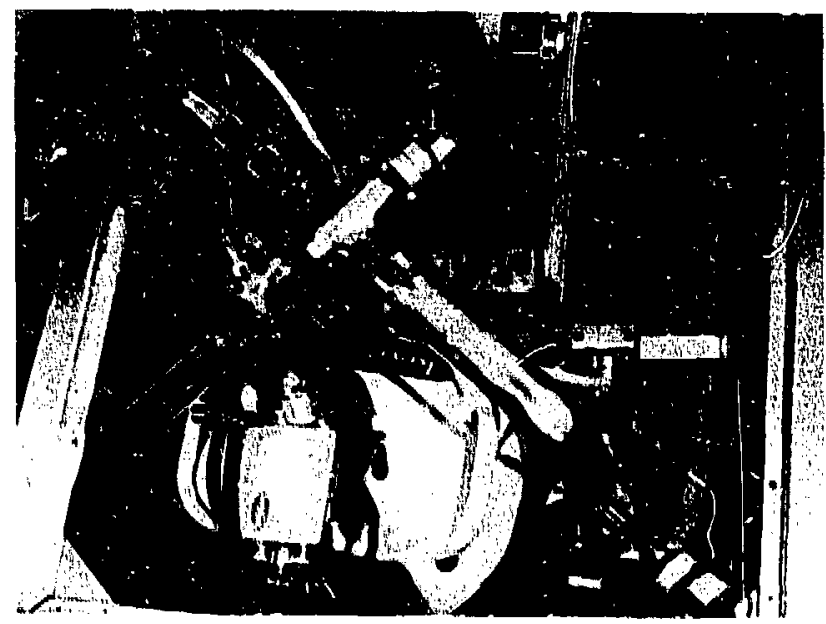

Figure 5. X-ray data head, top view.

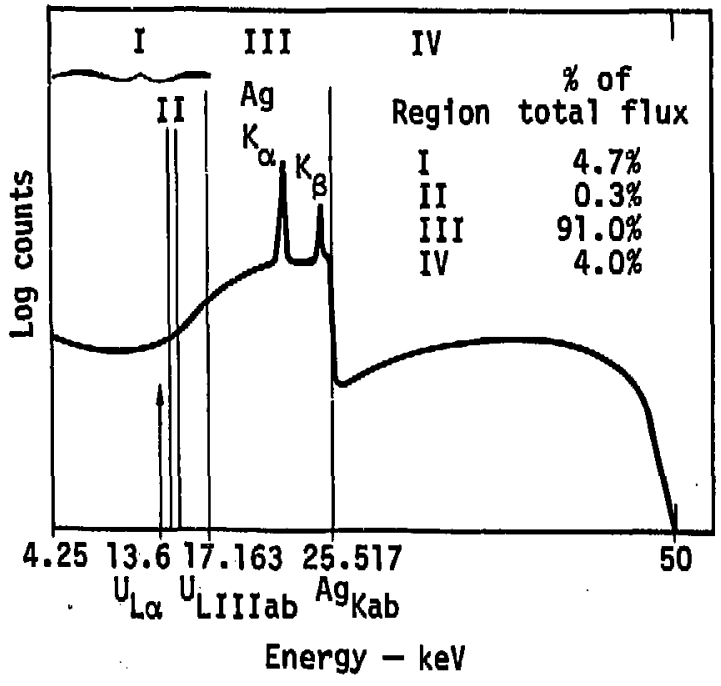

Figure 6. Energy spectrum of $x$-ray beam produced by the silver transmission anode tube; silver target 0.005 in. thick. 


\section{Scattering Chamber}

The sarple is held at 45 degrees to the exciting beam and to the detector by a plastic slide-holder. The chamber itself is made of aluminum, with lead shielding added to the outside for radiation protection of personnel.

Two sheets of titanium are placed on either side of the sample location so that the fluorescence from the titanium enters the detector directly. Figure 7 shows the scattering chamber, the plastic slide-holder, the titanium bean monitor sheets, and an actual samplo, as seen through the beam dump port. An additional beam monitor can be inserted behind the sample to provide absorption information. The use of any beam monitor increases the Comptonscattering in the spectral region of interest, but 1ts presence provides a normalization peak in each spectrum. The beam monitor is an "external standard" which completely removes the effect of fluctuations in beam fluence, all systern dead-time corrections, pulse pile-up rejection losses, and changes in geonetry.

The magnetic $\beta$-ray trap and the lead collimator (aluminumlined) are located between the scattering chamber and the detector.

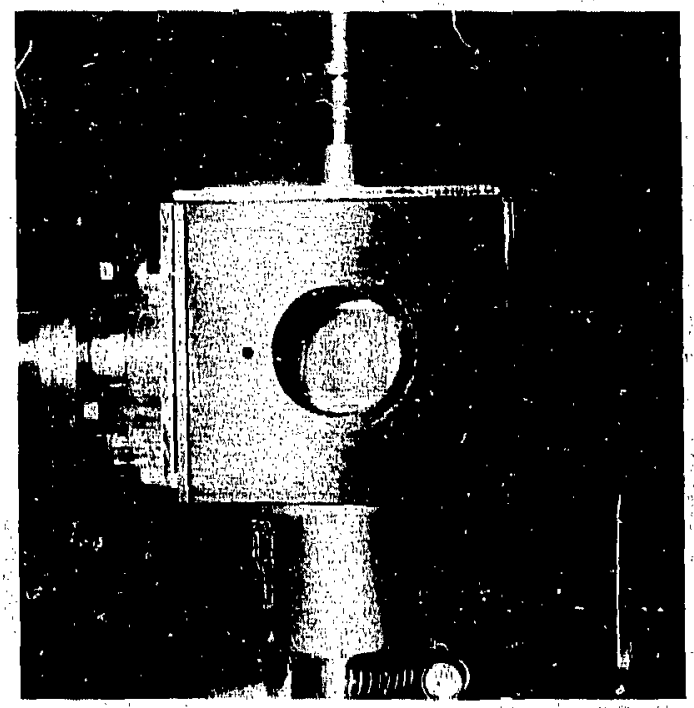

Figure 7. View of complete scattering chamber with sample and beam monitor as seen through the beam dump port. 


\section{Detector and Electronics}

The system has been operated with Si(Li) detectors and electronic packages obtained from two different comnercial sources. One detector is $10 \mathrm{~mm}^{2}$ in area by $2 \mathrm{~mm}$ deep, while the other is $30 \mathrm{~mm}^{2}$ by $3 \mathrm{~mm}$ deep. In both cases, the manufacturer developed special electronics packages to 1 llow the systems to operate in the large flux of high-energy $(100-\mathrm{keV}$ to 3 -MeV $) \gamma$-radiation from the sample. The $\gamma$-rays produce overload pulses in the detector. We find that the $\beta$-trap prevents any $\beta$-rays from reaching the detector, and the special electronics package allows the detector to operate in a $\gamma$-ray field of about $1 \mathrm{R} / \mathrm{hr}$ with only a $5 \%$ to $10 \%$ degradation in resolution. The detector resolution at $13.6 \mathrm{keV}$ with the radioactive sample in the chamber is about $210 \mathrm{eV}$, FWHM.

The electronics package contains a preamplifier (pulsedoptical feedback), an amplifier with pulse pileup refection and modifications for the overload gamma pulses, and high-voltage control and supply. A rate-meter was added to monitor the overall input count rate. Typical overload pulse rates are 3000 to 5000 cps, and the signal pulse rate is approximately the same.

\section{Sample Proparation}

The sample preparation equipment (FIg. 8) consists of a sintered stainless steel pellet which has a vacuum line attached. The vacuum line sucks a $0.5-\mathrm{mil}$ polycarbonate sheet onto the slightly concave surface of the steol pellet. One 50-microliter drop of dissolver solution is placed on the film at the center and allowed to dry;

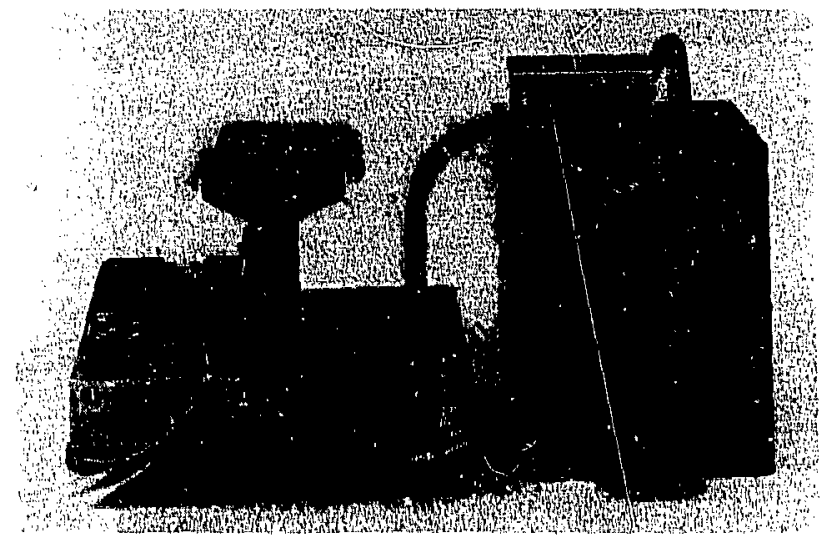

Figure 8. Sample preparation stand with heater control and polycarbonate film in place. 
this takes a few minutes with the help of an Infrared lamp or the heater element in the stand. After the sample is dry, adhesive is sprayed on the film and a second sheet of film is placed over the sample. This sandwich is then mounted in a standard 35-mm slide. Care must be taken to not allow large crystals to develop when the sample is drying, because they make an absorption correction necessary during analysis. We are currently exploring the use of freezedrying techniques for an alternate method of sample preparation. Prefreezing of the sample before evaporation of the water prevents the formation of large single crystals.

Figure 9 shows some actual samples being inserted into the scattering chamber. The slide-holder is withdrawn for display. Note the radiation damage to the bottom of glase storage bottle in the foregrourid.

\section{Analysis}

of the $104 \ell x$-ray lines of uranium and plutonium, only the 'Iranium $(L \alpha 1+2)$ and the plutonium $(L \alpha 1+2)$ are free from interference. The uraniun $(L \alpha)$ doublet is at atout $13.613 \mathrm{keV}$ and the plutonium (La) is at $14.279 \mathrm{keV}$, a differenc" of $666 \mathrm{oV}$. Figure 10 shows this part of a spectrum (uranfum ( $L l)$, uranium (La), and plutonium (LQ) peaks) of an actual dissolver-solution sample. The uranium-plutonium ratio was 250:1 and the sample was highly radioactive.. Figure 10 shows a simflar spectrum from a sample containing

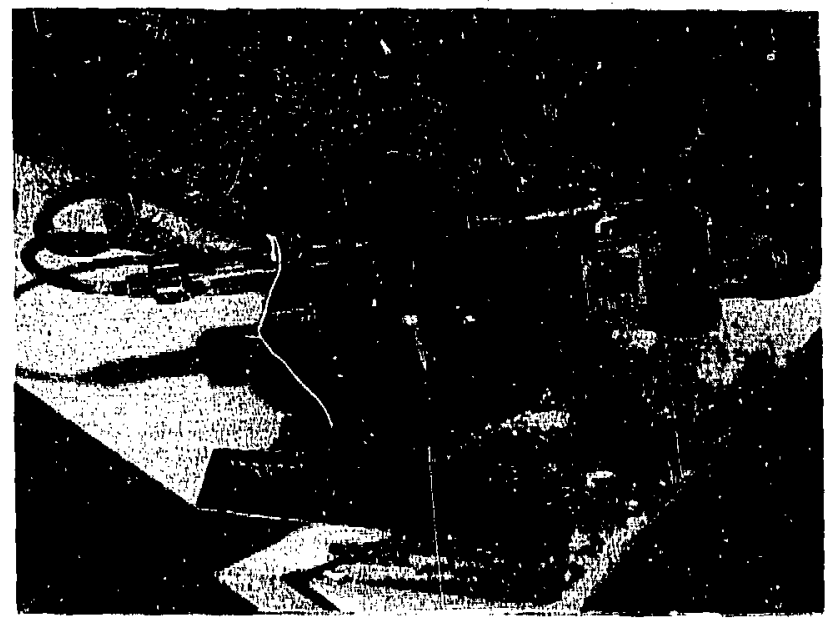

Figure 9. View of scattering chamber in use with various types of samples. 


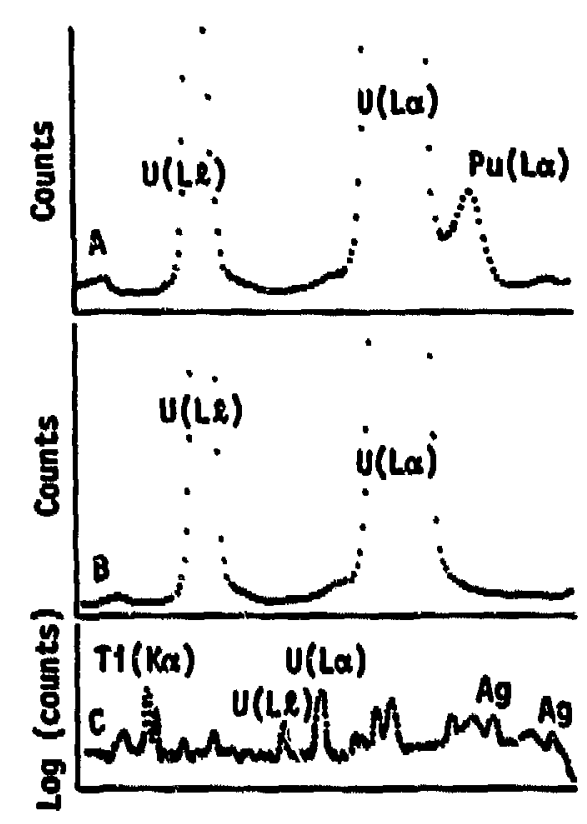

Figuro 10. Actial onergy spectra: (a) dissolver solution, U/Pu - 250; (b) uranium only, prepared standard; (c) 108 plot of complete spectrum of prepared standard (note titanium beam monitor poaks).

no plutonium or fission products; there is very little change in background or resolution. The primary analysis problem in using this data is to rennove the upper tail of the large uranium (La) peak from beneath the plutonium (La). We are currentiy working on a technique which uses a double gaussian with upper and lower folded tails to represent the shape of the poaks in this region.

Figure 10 shows a typical spectrum in a log plot. Note the titanium beam monitor peak and the uranium (La) peak. The net peak areas of these two peaks are ostained with ilnear background subtraction routines that use clear areas above and below the peaks. The uranium $(L \alpha)$ peak aroa is then divided by the titanium $(K \alpha+\beta)$ peak area and multiplied by constant:

We have begun extensive calibration experiments both at LLL and du Pont Savannah River. Initially, we used prepared standards with known quantities of urantum ranging from 1 to $100 \mathrm{\mu g}$, with no fission products. 
Our tests at LL have resulzed in a measured reproduclibility for a particular sample of 0.24 ( $1 \mathrm{sigma}$ ) and a vartance betwoen suples of supposedly equal masses of 0.68 ( $131 \mathrm{gma}$ ). We have not yot been able to check our standaxds by an Indepondent mothod.

The dete annlysis takes approximately 30 seconds and the typicul acquisition timo is about 10 minutes. Our reproducibility checks showed no dependence on count rate, on sample position, or on uranium awounts, to within 0.26 ( 1 sigma). With the prepared standards we huve novared the Ilnearity of the system for uranium mas to be 18 (1 algai) from 1 he to 58.1 ug totel uranium mass.

We aro grently ennouraged by these results and axe looking forwerd to using the sits of standards now bolng made at di Pont Suvennah RIVer. Those dtandards w111 contein the complete inventory of fission products and will havo vartous ratios of uraniun to plutontum.

\section{ACENOWLEDangNrs}

This work was performed under the auspices of the U.S. Atomic Energy Counission. The authors gratefully acknowledge the helpful efforts of R. Taylor, T. O. Hooger, R. Howell, and M. Coops in the dovelopment of this equipment. Wo also thank $R$. Jaroszesk1 of Muclear Puel Sorvices Company, and the four power companies (Pactelc Gas Electric, Yankee Atomic Electric Co., South Carolina Electric 6 Gas Co., and Consumers Power Co.) who donated the dissolver solutions from their reactor fuels.

\section{REPERENCE}

1. J. M. Jaklevic, R. D. Glaugue, D. F. Malone, and W. L. Searles, "Sma11 X-Ray Tubes for Energy D1spersive Analysis Using Sem1conductor Spectromoters," In kurt F. J. Heinrich, Bditor, Advances in X Ray Analysis, Vol. 15, p. 266-275, P1enum Pross (1972). 